\title{
Quaternary rupture behavior of the Karakoram Fault and its relation to the dynamics of the continental lithosphere, NW Himalaya- western Tibet
}

Journal Article

Author(s):

Houlié, Nicolas (D); Phillips, Richard J.

Publication date:

2013-06

Permanent link:

https://doi.org/10.3929/ethz-a-009774154

Rights / license:

In Copyright - Non-Commercial Use Permitted

Originally published in:

Tectonophysics 599, https://doi.org/10.1016/j.tecto.2013.03.029 


\section{Elsevier Editorial System(tm) for Tectonophysics}

Manuscript Draft

\section{Manuscript Number: TECT08413R1}

Title: Quaternary Rupture Behavior of the Karakoram Fault and its relation to the dynamics of the continental lithosphere, NW Himalaya-West Tibet

Article Type: Research Paper

Keywords: Geophysics -- Geology -- Stress transfer

Corresponding Author: Dr. nicolas houlie,

Corresponding Author's Institution: ETHZ

First Author: Nicolas Houlie

Order of Authors: Nicolas Houlie

Abstract: The Karakoram Fault is a major Tibet-bounding strike-slip system that partitions strain between the compressional regime of the NW Himalaya and the translational and extensional fault systems of Tibet[Searle, et al., 2011]. Although geodetic observations suggest that the fault is currently locked[Wright, et al., 2004], high millenial slip rate estimates infer a dominant role in continental deformation models[Loveless and Meade, 2011].

We examine all Quaternary data available for the Karakoram Fault and attempt to explain the temporal and spatial variability of fault slip rate. We show that Karakoram fault slip rate has been modulated by transient seismicity triggered by the activity associated with subduction of the Indian plate beneath Tibet.

Our model has implications for the understanding of stress transfer between large fault systems and their interaction with lithosphere deformation. We suggest that whilst the long-term deformation of Tibet may be modelled as partially viscous medium, the slip rates of major faults may vary by one order of magnitude during the Quaternary. Our analysis may resolve the frequently observed discrepancy between millenial and decadal records of fault slip rates. 


\section{Abstract}

16 The Karakoram Fault is a major strike-slip system that partitions strain between the

17 compressional regime of the NW Himalaya and the translational and extensional fault

18 systems of Western Tibet. Although seismic and geodetic observations suggest that the

19 fault is currently locked, high millenial slip rate infer a dominant role in the deformation

20 of Western Tibet. We examine all Quaternary data available for the Karakoram Fault and

21 attempt to explain the temporal and spatial variability of fault slip rate. We show that

22 Karakoram fault stress level could be modulated by Coulomb Stress changes associated

23 with varying seismicity on the subducting Indian plate beneath Western Tibet. Our model

24 has implications for the understanding of stress transfer between large fault systems and

25 their interaction with lithosphere deformation. We suggest that whilst the long-term

26 deformation of Tibet may be modelled as partially viscous medium, the slip rates of

27 major faults may vary by one order of magnitude during the Quaternary. Our analysis

28 may resolve the frequently observed discrepancy between millenial and decadal records

29 of fault slip rates. 


\section{Introduction} Science community between two end member views (Thatcher, 2009). At one end of the spectrum are those that argue deformation must be distributed throughout the continental lithosphere e.g. (England and Houseman, 1986; England and Molnar, 1990; Houseman and England, 1986b), which implies that continents can be modelled as a visco-elastic continuum with faults reflecting the near-surface expression of deformation which is distributed at depth. In this context, mantle or lithospheric flow may contribute or control accumulation of stress in the upper crust (Houseman and England, 1986a). The hypothesis of distributed deformation contrasts markedly with the opposing view that deformation is purely elastic and localised along major lithospheric-scale faults which separate crustal blocks e.g. (Avouac and Tapponnier, 1993; Tapponier et al., 2001; Tapponnier and Molnar, 1976; Tapponnier et al., 1982). In this model, deformation between block-bounding faults is limited, with the outcome that a small number of large faults must accommodate most of the stress generated by the relative motions plate motion. Other authors have attempted to reconcile these constrasting views by modelling deformation across a collage of microplates e.g. (Loveless and Meade, 2011; Meade and Hager, 2005; Thatcher, 2007).

1 Regardless of the model for continental deformation, a central tenet of each is to ascribe a role and significance to major faults within an actively deforming zone. Much of this debate has evolved through contrasting studies of how deformation is accommodated across the Himalaya-Tibet orogen. By viewing Tibet as a rigid block, the 
offsets and fast slip-rates. Conversely, these faults are seen as playing a minor role in the continuum model, which predicts low slip-rates, small offsets and limited continental extrusion. These contrasting models remain polarised in part due to the apparent disparity between modelled millenial and decadel slip-rates for these faults. This may be explained by the fact that none of the current models explore the influence of short- or long-term variability in slip rate for an individual fault, both of which are investigated here.

For the Altyn-Tagh Fault (ATF), millenial slip rates (SR) have previously been reported as a factor of three greater than inter-seismic geodetic estimates (Meriaux et al., 2005; Mériaux et al., 2004). However, after a careful reassessment of river bed mapping and data reanalysis, recent work along the central ATF (Cowgill et al., 2009; Gold et al., 2009; Gold and Cowgill, 2011) appears to reconcile long and short term estimates by determining a slip of $11 \pm 2 \mathrm{~mm} / \mathrm{yr}$ since 4-6 kyr, in agreement with geodetic, paleoseismic, and geologic measurements. However, for the Karakoram Fault (KF) sliprate datasets are more controversial, due in part to the exposure of the fault zone and the numerous studies utilising differing techniques. Unlike the Altyn Tagh in northern Tibet, the Karakoram displays extreme topographic differences and offset of lithologic units spanning the Miocene to Pleistocene (Murphy et al., 2010; Murphy et al., 2000; Murphy et al., 2002; Searle et al., 2010; Searle et al., 2011; Searle and Phillips, 2007; Streule et al., 2009; Zhang et al., 2011). Consequently, published slip rates that range from 0 to 30 $\mathrm{mm} / \mathrm{yr}$ (Figure 1b) have been derived from U-Pb (Phillips et al., 2004; Searle et al., 2010; Streule et al., 2009; Valli et al., 2008; Wang et al., 2013; Wang et al., 2012), ${ }^{39} \mathrm{Ar}-{ }^{40} \mathrm{Ar}$ (Searle and Phillips, 2007; Searle et al., 1998; Valli et al., 2007) and ${ }^{10}$ Be dating techniques along mid- to southern- sections of the fault (Brown et al., 2002; Chevalier, 2006; Chevalier et al., 2005a; Chevalier et al., 2012; Chevalier et al., 2004) in addition to 
82 field (Banerjee and Burgmann, 2002; Jade et al., 2004; Jade et al., 2011; Zhang et al., 83 2004). The diversity of slip rates estimates may be the consequence of various 84 geophysical processes involving various time-scales; interseismic motion might be more 85 visible for techniques sampling at greater depth (GPS or InSAR; Figure 1b).

Following re-analysis of published datasets (Table 1) that define the Quaternary to recent slip rate history of the Karakoram Fault(Brown et al., 2002; Brown et al., 2003; Chevalier, 2006; Chevalier et al., 2005a; Chevalier et al., 2004), we investigate the seismic behavior of the KF fault since the Middle Pleistocene, its present lack of seismicity and the apparent absence of Pleistocene offset toward its northern termination. We propose that the kinematic history of the Karakoram Fault is controlled largely by the interplay between Indian plate motion and the associated seismicity along its subducting plane in the NW Himalaya. Using this model, we are able to reconcile the spatial and temporal variability in published slip-rates and offsets along the length of the Karakoram Fault and are subsequently able to better define the role and significance of the fault in models of continental deformation.

\section{The Quaternary Rupture History of the Karakoram Fault}

$105 \mathrm{~N}^{\circ} 5^{\circ}$. As the Karakoram Fault is one of the longest strike slip faults in western Tibet, the 
106 remaining lateral vector of $14 \mathrm{~mm} / \mathrm{yr}$, orientated at $\mathrm{N} 135^{\circ}$, must be at least partially

107 accommodated along this structure during episodes of seismicity. Nevertheless, evidence

108 from InSAR analysis(Wang and Wright, 2012; Wright et al., 2004), coupled with

109 geomorphic evidence and a lack of significant seismicity along the fault (Figure 1.a), has

110 led some to suggest that segments of the Karakoram fault are no longer active 111 e.g.(Robinson, 2009b).

112 Utilizing the GPS velocity field available for the Tibetan plateau(Zhang et al., 113 2004) we determine that the present large scale strain-rate field for the Karakoram Fault 114 is dominated by strain generated by India/Eurasia motion across the collision zone, 115 providing a shear strain rate of $\sim 10^{-7}$ and a compressional strain rate limited to $\sim 10^{-8}$, 116 oriented toward $\mathrm{N}^{\circ} 5^{\circ}$ (i.e. placing the Karakoram Fault currently under compression). 117 The orientation of maximal strain rate is aligned with the SKS shear wave splitting 118 orientation $\left(\sim \mathrm{N} 60^{\circ}\right)$ (Herquel and Tapponnier, 2005; Jade et al., 2004), roughly 119 perpendicular to the fault. This may imply that crust and lithosphere are decoupled and/or 120 the mantle is infinitely strained (Chamberlain et al., submitted; Houlié et al., submitted; 121 Houlié and Stern, 2012; Molnar, 1999). Interestingly, orientation of the fast axis of shear 122 wave splitting is similar to the principal stress orientation $\left(\sigma_{H}\right)$ inferred from 123 microseismicity in this region (Zhu and Shi, 2011), which supports the hypothesis of 124 decoupling in the lithosphere. Whilst GPS data for this area is available, the network 125 distribution is insufficient to compute a high-resolution strain-rate map of western Tibet. 126 Previous studies of the Karakoram Fault suggest that estimates of Quaternary slip 127 rate imply secular variations in fault motion(Chevalier et al., 2005a). This hypothesis is 128 based upon the measurement of in situ cosmogenic isotope production within quartz 129 cobbles taken from Quaternary landform features offset by the Karakoram Fault. By 130 deriving both a surface age and a displacement, Chevalier et al. $(2005,2012)$ conclude 
131 that the millenial slip rate of the Karakoram Fault is an order of magnitude greater than

132 that determined by InSAR analysis(Wright et al., 2004). This may suggest that slip along

133 the fault may have changed markedly in recent times. However, the Chevalier et al.

134 (2005) study was contested on the basis that exposure ages were strongly influenced by

135 postdepositional processes and hence, for a scattered dataset, only the oldest boulder ages

136 can be used to conservatively assess surface age(Brown et al., 2005).

137 To obtain a slip rate $(S R)$, commonly the average age for each surface is divided

138 by the corresponding fault offset to obtain a local fault slip rate. Completing this task for

139 the various age/offset datasets allows us to resolve varying slip rates for different

140 segments of a fault. Definition of each fault segment used here (central, south-central and

141 south, Figures 1 and Table 1) is the same as adopted in published datasets chevalier

142 (Brown, 2002; Brown et al., 2005; Chevalier, 2006; Chevalier et al., 2005b; Chevalier et

143 al., 2004). For the Karakoram fault we compute a SR for each fault segment where the

144 oldest age is adopted for each segment. This allows us to check the precision of the age

145 computation if the data sampled are close in both time and space.

146 By independently computing the slip rate for different segments of the Karakoram

147 Fault (Figure 1), we find that slip rates are uniform in time (as suggested by (Chevalier et

148 al., 2012) for the entire KF) and space, with up to $3 \mathrm{~mm} / \mathrm{yr}$ of difference (Figure $2 \mathrm{a}$ ).

149 However, the SR time-series is not exempt from artificial variation. Indeed, older slip

150 rates depend on the relative age of the available terraces in a same area. Longer time gaps

151 will generate larger slip rates because each offset represents the accumulated seismic

152 deformation (non-linear of time) over the measured period.

153 Below, we define a new measure termed ,Instantaneous Slip Rate' which delimits

154 slip between observational/sampling periods and provides a history of millennial slip 
155 variability unlike the time-averaged slip rates discussed above and provides an insight

156 into the possible dynamics of the NW Himalaya-West Tibetan lithosphere.

157

158

159

160

161

162

163

164

165

166

167

168

169

170

171

172

173

174

175

176

177

\section{Defining 'Instantaneous Slip Rates' (ISR) from Geologic or Geomorphic Studies}

Slip rates determined by geological or surface dating techniques are essentially a long-term time-integrated averaged rate, i.e. a surface age and offset are determined and

$S R=\frac{a g e}{\sum d_{i}}$. Conversely, geodetic techniques define slip rates that are 'time-stamped' at the middle of the data collection period. Geodetic slip rates could be compared to very short-term slip rates provided by e.g. cosmogenic exposure dating. However, geodetic slip rates cannot be compared directly to slip estimates derived from Pleistocene or older surface ages because the latter is the ratio of all cumulative offsets accrued since the dated surface was formed. Below, we explore a method to determine the variability of fault slip rate between two periods of interest and interrogate constraints on the relative timing of past events.

Let $d$ be the offset, the sum of all the offsets accumulated over a period of time delimited by times $\mathrm{t} 1$ and $\mathrm{t} 2$ :

$$
d=\int_{t_{1}}^{t_{2}} S R d t=\sum_{i=1}^{n}\left(S R_{i} \times t_{i}\right)
$$

Since $d$ is a cumulative value it does not reflect the variability of displacement through time. SR is a measure of the seismicity that actually occurred since an age time. For a geomorphic surface offset $\left(d_{\text {cosmo }}\right)$ of known age derived from e.g. cosmogenic exposure dating ( age $\left._{\text {cosmo }}\right)$, then: 


$$
d_{\text {cosmo }}=S R \text { age } \text { cosmo }_{\text {Eq. }}(2)
$$

For Equation 2, SR cannot be compared with geodetic techniques because it is

180 derived by measuring a cumulative surface offset and a surface age, which predates the

181 absolute timing of an initial rupture and thus provides a minimum value of slip. $S R_{\min }$ and

$182 d_{\text {cosmo }}$ are not time-stamped because $a g e_{\text {cosmo }}$ defines a stabilization age for the offset

183 surface. Assuming the age distribution to be scattered on a surface, age $e_{\text {cosmo }}$ would be the

184 oldest age on that surface.

185 Instead of defining the slip rate $S R$ by using the age of the sample and 186 accumulated offset we propose a method to time-stamp each sample. We thus move away 187 from the representations of slip rate described by Equations 1 and 2, and instead define an 188 'Instantaneous Slip Rate', ISR, which is computed by using the slip-rate defined over a 189 period of time delimited by time $t_{1}$ and $t_{2}$, e.g.:

$$
I S R_{2-1}=\frac{d_{\mathrm{cos} m o 2}-d_{\mathrm{cos} m o 1}}{a g e_{2}-\operatorname{ag} e_{1}}
$$

$$
\frac{\partial I S R_{2-1}}{\left|I S R_{2-1}\right|}=\frac{\partial a g e_{1}}{\left|a g e_{1}\right|}+\frac{\partial a g e_{2}}{\left|a g e_{2}\right|}+\frac{\partial d_{\cos m o 1}}{\left|d_{\cos m o 1}\right|}+\frac{\partial d_{\cos m o 2}}{\left|d_{\cos m o 2}\right|}
$$

195

196 Based on the published KF cosmogenic dataset (Brown, 2002; Chevalier et al.,

197 2005, Chevalier et al., 2012), which includes all known field uncertainties and relates to 198 the instantaneous behavior of the fault, the calculation of ISR uncertainties vary from $19951 \%$ to $150 \%$. 
Importantly, ISR tells us that the Karakoram Fault slip rate behavior changed 201 dramatically at $\sim 50 \mathrm{kyr}$, displaying a marked decrease in seismic activity from $5 \pm 1$ $202 \mathrm{~mm} / \mathrm{yr}$ to $0 \pm 2 \mathrm{~mm} / \mathrm{yr}$ (Figure 2). The magnitude in this change of slip rate cannot be 203 explained by the effect of glacial unloading (Hetzel and Hampel, 2005) associated with 204 the last period of deglaciation in the area(Owen et al., 2008).

205 Given the current low slip rate it is necessary to consider where strain may be 206 accommodated across the region. The pattern of seismicity in western Tibet (Figure 1) 207 does not suggest that any major fault sytem is currently offloading the Karakoram Fault. 208 Below, we explore a mechanism that may explain the suggested decrease in seismicity 209 since 50Kyr and discuss stress accumulation across the region.

211 Stress level history along the Karakoram Fault: influence of the Himalayan frontal 212 thrust system (HTF) In order to generate an earthquake along a strike-slip fault, three conditions are 215 necessary: (1) the fault needs to be stress-loaded, (2) the principal stress axes $\sigma$ should be 216 of different amplitudes $\left(\sigma_{1}>\sigma_{2}>\sigma_{3}\right.$, where $\sigma_{1}$ and $\sigma_{2}$ are the principal components of 217 horizontal stress and $\sigma_{3}$ the vertical stress), and (3) the stress axes must be oriented 218 appropriately (i.e. $\sigma_{1}$ not parallel to strike). Since the stress axes orientations are not 219 known, we assume that the Karakoram Fault strain and stress axes (related to India220 Eurasia collision) are aligned, as suggested by our comparision of the GPS strain field, 221 the fast polarization of SKS seismic waves and the local stress principal axes (above). 222 This is expected, as diverging stress and strain axes would suggest the recent occurrence 223 of a large seismic event. In such a case, the seismicity level should be higher than it is at 224 present. The low level of seismicity observed along the Karakoram Fault suggests that the 
225 accumulated stress must be distributed across the collision zone. If we assume that (1) the 226 load of the fault has been sustained by a constant northward motion of India over the last $2271 \mathrm{Myr}$, and (2) the Karakoram Fault accumulates only 30 to $50 \%$ of this stress generated 228 by the continental collision in western Tibet, then the long-term slip-rate of Karakoram 229 Fault would be $5 \pm 3 \mathrm{~mm} / \mathrm{yr}$. At the present collision rate, the stress accumulated should be 230 able to generate a seismic sequence containing at least one Mw8.0 ( 2 meters of slip) 231 every 1 kyr.

232 We know little about the stress accumulated along the Karakoram Fault, but as the 233 strain rate field is dominated by shear it is reasonable to assume that the stress 234 components are different. In order for the fault to slip what is required is a process that 235 can (1) change the background stress field, (2) sustain stress axes of different amplitudes, 236 at least temporarilly, and (3) overcome the background stress field. We propose that such 237 conditions are created following a significant earthquake or earthquake sequence 238 occurring along the subducting Indian plate, south of the Karakoram Fault.

239 Below, we test whether a single major event along the Indo-Asian collision zone 240 in the NW Himalaya may alter the stress level along the KF. In the Supplementary 241 Materials we also explore the effect of an earthquake sequence of Mw8.0 events. For 242 both cases we assume that the KF strain field can be deconvoluted into steady-state 243 (regional long-term) and transient (local short-term) strain components:

$$
\varepsilon_{i j}^{K F}(t)=\dot{\varepsilon}_{i j} \times \Delta t-\sum_{i=1}^{n} \Delta \varepsilon_{i j}^{H F T} \times \delta\left(t_{i}\right)
$$

245 The first term corresponds to the shortening between India and Eurasia since the 246 beginning of the seismic cycle (or since the lowest strain value). The second term 247 represents the seismic strain change for a single earthquake or a sequence of $n$ events 248 along the subducting plane (denoted as HFT in Eq.5). Both terms should balance on the 
249 very long term: at the end of seismic cycle (when most of the stress is released after a 250 major thrust event), ${ }_{i j}^{K F}(t)$ is minimal. A-priori we can assume that over a seismic cycle, 251 the stress is entirely released by the seismicity along the subducting plane. This would 252 imply that the magnitude of the transfered stress is constant along the Karakoram Fault. 253 It has been shown that for large events $(M>8)$, the coseismic (Ghimire et al., 254 2008; Lei et al., 2011; Uchida et al., 2009) and postseismic (Uchida et al., 2009) 255 Coulomb stress changes may effect crustal stress levels thousands of kilometers away 256 from the seismic source.

257 For a single earthquake, we calculate the Coulomb stress changes in a purely 258 elastic medium (Figure 3) and the strain fields generated by various sized earthquakes 259 rupturing along the collision zone in the NW Himalaya (Table S1). In order for a 260 subduction-related earthquake to pre-condition the Karakoram Fault for a future seismic 261 event, the temporary stress axis rotation needs to be of the order $>20^{\circ}$ counter-clockwise. 262 In order to define the length and mean slip of characteristic events we utilize a scaling 263 law(Wells and Coppersmith, 1994) for each characteristic event (Table S1). We assume 264 the dip angle along the subducting plane was equal to $16^{\circ}$ for all events.

265 Figure $3 \mathrm{a}$ shows the stress changes in the elastic surrounding medium induced 266 along Karakoram Fault by a seismic event $(\mathrm{Mw} \sim 8.0)$ rupturing a segment of the NW 267 Himalaya subduction zone. A-priori, we would expect any seismic event to unload the 268 stress along the Karakoram Fault and to inhibit seismicity. We find that if this assumption 269 is confirmed, in limited areas, the shear and normal stress changes are respectively 270 increased and decreased, which encourages triggering or promotes a future earthquake 271 along the KF (Figure 3a, 3b). We also confirm that a strain of $10^{-7}$ may be imposed along 272 the KF (Figure $3 \mathrm{~b}$ ) and that, over a short time window, would allow the triggering of an 273 large mainshock along KF. 
In order to test whether the strain accumulated along KF could be sustained over a

275 long sequence of seismic events, we compute the stress change associated with a spatially

276 randomized distribution of seismicity along the subduction zone, we show that a small

277 rupture gap along the thrust front can preserve stress accumulated along the KF and that 278 at the edges of the rupture zone, the transient strain field $\Delta \varepsilon_{i,}$ is misaligned with the 279 strain-rate field .. which, as stated above, is a requirement for an earthquake to happen 280 along the Karakoram Fault.

281 The location along the Karakoram Fault at which stress changes from negative 282 (inhibiting slip) to positive (promoting slip) is a function of the location of the seismic 283 event along the collision zone: the strain transition will occur toward the southern end of 284 the Karakoram Fault if the subduction-related earthquake moves to the southeast. 285 Regardless of the location of the subduction-related seismic event, under the present 286 boundary conditions, the northern segment of the Karakoram Fault is always inhibited 287 with regard seismic loading and may explain the observation that no Quaternary offsets 288 are evident on the northern section of the KF(Robinson, 2009a; Robinson, 2009b). If the 289 subduction-related rupture event is located further south along the collision zone, then the 290 lateral extent of inhibited slip increases toward the southern end of the fault. 
293

294

295

296

297

298

299

300

301

302

303

304

305

306

307

308

309

310 Acknowledgments

311

312 this work. The editor and an aynonomous reviewer are thanked for their constructive

We define the Quaternary rupture behaviour of the Karakoram Fault by derivation of the 'Instantaneous Slip Rate' history. We suggest that the KF likely experiences high variations in seismic activity over millenial (or shorter) time scales and that it in a period of quiescence. We demonstrate that the KF rupture history may be modulated by seismic activity along the subducting Indian plate to the southwest. The relative position of the KF and the subducting plate results in the northern segment of the Karakoram Fault remaining inhibited to dextral slip, whilst slip is promoted toward the southern segement of the fault. This may explain why such slip variability is observed along the length of the fault and why the northern termination lacks evidence of Quaternary offset. We suggest that the structural features of western Tibet need not be linked to the deep lithosphere as proposed for the dynamics of southern Tibet (Copley et al., 2011) and that the level of seismicity is mostly due to the adjustment of stress across large scale fault systems, the lateral relative plate motions being mostly accommodated along $\mathrm{KF}$. We therefore suggest that KF is not deeply rooted in the mantle lithosphere as suggested for other large continental strike slip faults (Polet and Kanamori, 2002).

313 comments. 
Avouac, J.-P., Tapponnier, P., 1993. Kinematic model of active deformation in central Asia. Geophys. Res. Lett. 20, 895-898.

Banerjee, P., Burgmann, R., 2002. Convergence across the northwest Himalaya from GPS measurements. Geophys. Res. Lett. 29, 30-34.

Brown, E.T., 2002. Slip rates of the Karakorum fault, Ladakh, India, determined using cosmic ray exposure dating of debris flows and moraines. J Geophys Res 107. Brown, E.T., Bendick, R., Bourles, D.L., Gaur, V., Molnar, P., Raisbeck, G.M., Yiou, F., 2002. Slip rates of the Karakorum fault, Ladakh, India, determined using cosmic ray exposure dating of debris flows and moraines. J. Geophys. Res. 107, 2192.

Brown, E.T., Bendick, R., Bourles, D.L., Gaur, V., Molnar, P., Raisbeck, G.M., Yiou, F., 2003. Early Holocene climate recorded in geomorphological features in Western Tibet. Palaeogeography Palaeoclimatology Palaeoecology 199, 141-151.

Brown, E.T., Molnar, P., Bourles, D.L., 2005. Comment on "Slip-rate Measurements on the Karakorum Fault May Imply Secular Variation in Fault Motion, by M.L. Chevalier et al., . Science 411.

Chamberlain, C.P., Houlié, N., Bentham, H., Stern, T., submitted. Lithosphere strain and stress fields near the San Andreas Fault. EPSL.

Chevalier, 2006. Détermination, par datations cosmogéniques, des variations de la vitesse de glissement sur la Faille du Karakorum (Tibet) et reconstruction paleoclimatique depuis 200 ka. PhD thesis - Institut de Physique du Globe de Paris, 315.

Chevalier, M.-L., Ryerson, F.J., Tapponnier, P., Finkel, R.C., Van Der Woerd, J., Li., H., Liu, Q., 2005a. Slip-rate measurements on the Karakoram fault may imply secular variations in fault motion. Science 237. Chevalier, M.-L., Tapponnier, P., Van der Woerd, J., Ryerson, F.J., Finkel, R.C., Li, H., 2012. Spatially constant slip rate along the southern segment of the Karakorum fault since 200ka. Tectonophysics 530-531, 152-179.

Chevalier, M.L., Ryerson, F.J., Tapponnier, P., Finkel, R.C., Van Der Woerd, J., Haibing, L., Qing, L., 2005b. Slip-rate measurements on the Karakorum Fault may imply secular variations in fault motion. Science 307, 411-414. Chevalier, M.L., Tapponnier, P., Ryerson, R., Finkel, R., Van Der Woerd, J., Liu, Q., 2004. Determination of the Slip-rate on the Karakorum Fault (Tibet) by Dating of Radioisotopes (10Be). Geophysical Research Abstracts 6. Copley, A., Avouac, J.-P., Wernicke, B.P., 2011. Evidence for mechanical coupling and strong Indian lower crust beneath southern Tibet. Nature 472, 81. Cowgill, E., Gold, R., Chen, X., Wang, X., Arrowsmith, J., Southon, J., 2009. Low Quaternary slip rate reconciles geodetic and geologic rates along the Altyn Tagh fault, northwestern Tibet. Geology 37.

DeMets, C., Gordon, R.G., Argus, D.F., 2010. Geologically current plate motions. Geophys. J. Int. 181, 1-80.

Dziewonski, A.M., Chou, T.-A., Woodhouse, J.H., 1981. Determination of earthquake source parameters from waveform data for studies of global and regional seismicity. J Geophys Res 86, 2825-2852.

England, P., Houseman, G., 1986. Finite Strain Calculations of Continental Deformation .2. Comparison with the India-Asia Collision Zone. J Geophys Res-Solid 91, 3664-3676. England, P., Molnar, P., 1990. Surface Uplift, Uplift of Rocks, and Exhumation of Rocks. Geology 18, 1173-1177. 
363 Ghimire, S., Katsumata, K., Kasahara, M., 2008. Spatio-temporal evolution of Coulomb stress in the Pacific slab inverted from the seismicity rate change and its tectonic interpretation in Hokkaido, Northern Japan. Tectonophysics 455, 25-42. Gold, R., Cowgill, E., Arrowsmith, J., Gosse, J., Chen, X., Wang, X., 2009. Riser diachroneity, lateral erosion, and uncertainty in rates of strike-slip faulting: A case study from Tuzidun along the Altyn Tagh Fault, NW China. J. Geophys. Res. 114. Gold, R.D., Cowgill, E., 2011. Deriving fault-slip histories to test for secular variation in slip, with examples from the Kunlun and Awatere faults. Earth Planet Sc Lett 301, 52-64. Herquel, G., Tapponnier, P., 2005. Seismic anisotropy in western Tibet. Geophys Res Lett 32.

Hetzel, R., Hampel, A., 2005. Slip rate variations on normal faults during glacialinterglacial changes in surface loads. Nature 435, 81-84.

Houlié, N., Cornwell, D., Green, C., submitted. Regional variations in lithosphere deformation beneath the British Isles. Earth \& Planet. Sc. Lett. Houlié, N., Stern, T., 2012. A comparison of GPS solutions for strain and SKS fast directions: implications for modes of shear in the mantle of a plate boundary zone. Earth Planet. Sci. Lett. 345-348, 117-125.

Houseman, G., England, P., 1986a. Finite Strain Calculations of Continental Deformation .1. Method and General Results for Convergent Zones. J Geophys Res-Solid 91, 36513663.

Houseman, G.A., England, P.C., 1986b. Finite strain calculations of continental deformation .1. Method and general results for convergent zones. J. Geophys. Res. 91, 3651-3663.

Jade, S., Bhatt, B.C., Yang, Z., Bendick, R., Gaur, V.K., Molnar, P., Anand, M.B., Kumar, D., 2004. GPS measurements from the Ladakh Himalaya, India: Preliminary tests of plate-like or continuous deformation in Tibet. Geological Society of America Bulletin 116, 1385-1391. Jade, S., Raghavendra Rao, H.J., Vijayan, M.S.M., Gaur, V.K., Bhatt, B.C., Kumar, K., Jaganathan, S., Ananda, M.B., Dileep Kumar, P., 2011. GPS-derived deformation rates in northwestern Himalaya and Ladakh. 100.

Lei, X., Xie, C., Fu, B., 2011. Remotely triggered seismicity in Yunnan, southwestern China, following the 2004 Mw9.3 Sumatra earthquake. Jour. Geophys. Res. Solid Earth 116.

Loveless, J.P., Meade, B.J., 2011. Partitioning of localized and diffuse deformation in the Tibetan Plateau from joint inversions of geologic and geodetic observations. Earth Planet Sc Lett 303, 11-24.

Meade, B.J., Hager, B.H., 2005. Block models of crustal motion in southern California constrained by GPS measurements. J Geophys Res-Sol Ea 110.

Meriaux, A., Tapponnier, P., Ryerson, F., Xu, X., King, G., Van der Woerd, J., Finkel, R., Li, H., Caffee, M., Xu, Z., Chen, W., 2005. The Aksay segment of the northern Altyn Tagh fault: Tectonic geomorphology, landscape evolution, and Holocene slip rate. J. Geophys. Res. 110.

Mériaux, A.-S., Ryerson, F.J., Tapponnier, P., Van der Woerd, J., Finkel, R.C., Xiwei, X., Zhiqin, X., Caffee, M.W., 2004. Rapid slip along the central Altyn Tagh Fault: Morphological evidence from Cherchen He and Sulamu Tagh. J. Geophys. Res. 109. Molnar, P., 1999. Continuous Deformation Versus Faulting Through the Continental Lithosphere of New Zealand. Science 286, 516-519.

Murphy, M.A., Sanchez, V., Taylor, M.H., 2010. Syncollisional extension along the India-Asia suture zone, south-central Tibet: Implications for crustal deformation of Tibet. 
413 Murphy, M.A., Yin, A., Kapp, P., Harrison, T.M., Lin, D., Guo, J.H., 2000. Southward 414 propagation of the Karakoram fault system, southwest Tibet: Timing and magnitude of 415 slip. Geology 28, 451-454.

416 Murphy, M.A., Yin, A., Kapp, P., Harrison, T.M., Manning, C.E., Ryerson, F.J., Ding, 417 L., Guo, J.H., 2002. Structural evolution of the Gurla Mandhata detachment system, 418 southwest Tibet: Implications for the eastward extent of the Karakoram fault system. 419 Geological Society of America Bulletin 114, 428-+.

420 Owen, L.A., Caffee, M.W., Finkel, R., YEONG, B.S., 2008. Quaternary glaciation of the 421 Himlayan-Tibetan orogen. Journal of Quaternary Science 23, 513-531.

422 Phillips, R.J., Parrish, R.R., Searle, M.P., 2004. Age constraints on ductile deformation 423 and long-term slip rates along the Karakoram fault zone, Ladakh. Earth Planet Sc Lett 424 226, 305-319.

425 Polet, J., Kanamori, H., 2002. Anisotropy beneat California: shear wave splitting 426 measurements using a dense broadband array. Geophys. J. Int. 149, 313-327.

427 Robinson, A.C., 2009a. Evidence against Quaternary slip on the northern Karakorum 428 Fault suggests kinematic reorganization at the western end of the Himalayan-Tibetan 429 orogen. Earth Planet Sc Lett 286, 158-170.

430 Robinson, A.C., 2009b. Geologic offsets across the northern Karakorum fault: 431 Implications for its role and terrane correlations in the western Himalayan-Tibetan 432 orogen. Earth Planet Sc Lett 279, 123-130.

433 Searle, M., Parrish, R.R., Thow, A.V., Noble, S.R., Phillips, R.J., Waters, D.J., 2010. 434 Anatomy, age and evolution of a collisional mountain belt: the Baltoro granite batholith 435 and Karakoram Metamorphic Complex, Pakistani Karakoram. J. Geol. Soc. London 167. 436 Searle, M.P., Elliott, J.R., Phillips, R.J., Chung, S.L., 2011. Crustal-lithospheric structure 437 and continental extrusion of Tibet. Journal of the Geological Society 168, 633-672. 438 Searle, M.P., Phillips, R.J., 2007. Relationships between right-lateral shear along the 439 Karakoram fault and metamorphism, magmatism, exhumation and uplift: evidence from 440 the K2-Gasherbrum-Pangong ranges, north Pakistan and Ladakh. J GEOL SOC 441 LONDON 164, 439-450.

442 Searle, M.P., Weinberg, R.F., Dunlap, W.J., 1998. Transpressional tectonics along the 443 Karakoram fault zone, northern Ladakh: constraints on Tibetan extrusion. Geol. Soc. 444 Lond., London.

445 Streule, M.J., Phillips, R.J., Searle, M.P., Waters, D.J., Horstwood, M.S.A., 2009.

446 Evolution and chronology of the Pangong Metamorphic Complex adjacent to the 447 Karakoram Fault, Ladakh: constraints from thermobarometry, metamorphic modelling 448 and U-Pb geochronology. J. Geol. Soc. London 166, 919-932.

449 Tapponier, P., Xu, Z., Roger, F., Meyer, B., Arnaud, N., Wittlinger, G., Yang, J., 2001. 450 Oblique stepwise rise and growth of the Tibetan plateau. Science 294, 1671-1677.

451 Tapponnier, P., Molnar, P., 1976. Slip-line field theory and large-scale continental 452 tectonics. Nature 264, 319-324.

453 Tapponnier, P., Peltzer, G., Le Dain, A.Y., Armijo, R., Cobbold, P., 1982. Propagating 454 extrusion tectonics in Asia: new insights from simple experiments with plasticine.

455 Geology 10, 611-616.

456 Thatcher, W., 2007. Microplate model for the present-day deformation of Tibet. J

457 Geophys Res-Sol Ea 112, 13.

458 Thatcher, W., 2009. How the Continents Deform: The Evidence From Tectonic

459 Geodesy*. Annual Review of Earth and Planetary Sciences 37, 237-262.

460 Toda, S., Stein, R.S., 2002. Response of the San Andreas Fault to the 1983 Coalinga-

461 Nuñez Earthquakes: An Application of Interaction-based Probabilities for Parkfield. J.

462 Geophys. Res. 107. 
463

464

465

466

467

468

469

470

471

472

473

474

475

476

477

478

479

480

481

482

483

484

485

486

487

488

489

490

491

492

493

494

495

496

497

Uchida, K., Yui, S., Miura, S., Matsuzawa, T., Hasegawa, A., Motoya, Y., Kasahara, M., 2009. Quasi-static slip on the plate boundary associated with the 2003 M8.0 Tokachi-oki and 2004 M7.1 off-Kushiro earthquakes, Japan. Gondwana Research 16.

Valli, F., Arnaud, N., Leloup, P.H., Sobel, E.R., Maheo, G., Lacassin, R., Guillot, S., Li, H., Tapponnier, P., Xu, Z., 2007. Twenty million years of continuous deformation along the Karakorum fault, western Tibet: A thermochronological analysis. Tectonics 26. Valli, F., Leloup, P., Paquette, J., Arnaud, N., Li, H., Tapponnier, P., Lacassin, R., Guillot, S., Liu, D., Deloule, E., Xu, Z., Maheo, G., 2008. New U-Th/Pb constraints on timing of shearing and long-term slip-rate on the Karakorum fault. Tectonics 27.

Wang, H., Wright, T.J., 2012. Satellite geodetic imaging reveals internal deformation of western Tibet. Geophys. Res. Lett. 39.

Wang, S., Murphy, M., Phillips, R.J., Wang, C., 2013. Reply to Comment on

"Displacement along the Karakoram fault, NW Himalaya, estimated from LA-ICPMS U$\mathrm{Pb}$ dating of offset geologic" by Leloup et al. Earth \& Planet. Sc. Lett. 363, 246-248.

Wang, S., Wang, C., Phillips, R.J., Murphy, M., 2012. Small-scale offset of the Karakoram Fault constrained by robust LA-ICP-MS U-Pb dating of displaced geological markers. Earth \& Planet. Sc. Lett. 337-338, 156-163.

Wells, D.L., Coppersmith, K.J., 1994. New empirical relationships among magnitude, rupture length, rupture width, rupture area, and surface displacement. Bulletin of Seismological Society of America 84, 974-1002.

Wessel, P., Smith, W.H.F., 1991. Free software Helps Maps and Display Data. EOS 72, 445-446.

Wright, T.J., Parsons, B., England, P.C., Fielding, E.J., 2004. InSAR observations of low slip rates on the major faults of western Tibet. Science 305, 236-239.

Zhang, P.Z., Shen, Z., Wang, M., Gan, W.J., Burgmann, R., Molnar, P., 2004.

Continuous deformation of the Tibetan Plateau from global positioning system data. Geology 32, 809-812.

Zhang, R., Murphy, M.A., Lapen, T.J., Sanchez, V., Heizler, M., 2011. Late Eocene crustal thickening followed by Early-Late Oligocene extension along the India-Asia suture zone: Evidence for cyclicity in the Himalayan orogen. Geosphere 7, 1249-1268. Zhu, S., Shi, Y., 2011. Estimation of GPS strain rate and its error analysis in the Chinese continent. Journal of Asian Earth Sciences 40, 351-362. 
499 Figure 1a: Tectonic setting of the Karakoram Fault, western Tibet. Seismicity derived 500 from Centroid Moment Tensor(Dziewonski et al., 1981) (all earthquakes available are 501 plotted) and ANSS catalogues (M>3 since May, 21, 1962) demonstrate a very low level 502 of stress accumulation in this region. KF - Karakoram Fault; ATF - Altyn Tagh Fault. 503 Locations 1-4 represent the cosmogenic exposure dating sites of Chevalier et al. (2004, 504 2005, 2006) [1) and 2) South site, 3) South-central site] and Brown et al. (2004) [4) 505 Central site in Ladakh]. See text for discussion.

507 Figure 1b: Comparison between slip rates derived from Quaternary and geodetic studies 508 for the Karakoram Fault ( $1 \sigma$ error bars). We plot each solution for its apppropriate depth. 509 This Figure demonstrates that the previous slip-rate estimates (Chevalier, 2006; Chevalier 510 et al., 2005a; Chevalier et al., 2004) exhibit sufficient dispersion such that they overlap 511 with slip estimates derived by late Quaternary (Brown et al., 2002) or geodetic (Wright et 512 al., 2004) studies. The plotted error bars for all studies are compatible for those derived 513 from other well-studied faults.

515 Figure 2a: Slip-rate (SR) estimates along the southern Karakoram Fault for the last 200 516 kyr for individual sites. SR suggests that different KF segments are expressing various 517 levels of seismic activity and that stress was accumulated in areas between south-central 518 and south segments over the period 50-100kyr. Central segment shows a constant 519 decrease of slip rates since $20 \mathrm{kyr}$.

521 Figure 2b: ISR Time Series for the last $200 \mathrm{kyr}$ for the South-central, South and Central 522 segments of the southern Karakoram fault. All KF segments experienced a decrease of 
523 seismicity since at least $10 \mathrm{kyr}$ with a peak of seismic activity occuring between $10 \mathrm{kyr}$

524 (central segment) and 100kyr (south segment). We suggest differiential strain

525 accumulated between segments over time and that stress was transferred between

526 segments over large time periods.

527

528 Figure 3a: Stress changes induced by a M8.0 along the Himalayan Front Thrust (HTF).

529 The KF is indicated by a wide blue line. In this model, the seismic rupture intersect with

530 the surface. The values presented on this Figure have been computed using the Coulomb

5313.3 package(Toda and Stein, 2002) and interpolated using a spline interpolation Generic

532 Mapping tool function surface (with a spacing of $100 \mathrm{~km}$ )(Wessel and Smith, 1991). See

533 Figure S1 of Supplementary Materials to see the strain pattern associated with this event.

535 Figure 3b: Cross-section of stress field changes along KF (see Figure 3a for a map 536 view). We find that while the normal stress is increased and the shear stress is decreased 537 in some areas of KF, the opposite behavior can be made in some other areas. We suggest 538 these locations are the possible starting point for triggered events along KF. 


\begin{tabular}{|c|c|c|c|c|c|c|c|c|c|}
\hline \multirow[b]{2}{*}{ Area } & \multirow[b]{2}{*}{ Age (ky) } & \multirow{2}{*}{$\begin{array}{l}\text { Age } \\
\text { unc. } \\
(1 \sigma \\
\text { ky) }\end{array}$} & \multirow{2}{*}{\multicolumn{2}{|c|}{$\begin{array}{cc} & \text { Offse } \\
& \text { t unc. } \\
\text { Offset } & \text { (m) } \\
\text { (m) } & \end{array}$}} & \multirow[b]{2}{*}{$\begin{array}{c}\text { SR } \\
(\mathrm{m} / \mathrm{y})\end{array}$} & \multirow[b]{2}{*}{ Time (ky) } & \multicolumn{3}{|c|}{$\begin{array}{c}\text { ISR unc. } \\
(\%)\end{array}$} \\
\hline & & & & & & & $\operatorname{ISR}(\mathbf{m} / \mathbf{y})$ & & Segment \\
\hline & & NA & & 0.01 & & & & & \\
\hline \multirow[t]{2}{*}{ Central } & 0.010 & & $0 ?$ & & 0 & 0 & 0.0000 & & Ladakh \\
\hline & & 2 & & 0.1 & & & & 71 & \\
\hline \multirow[t]{2}{*}{ Central } & 3.022 & & 2 & & 0.0007 & 1.516 & 0.0028 & & Ladakh \\
\hline & & 7 & & 5 & & & & 56 & \\
\hline \multirow[t]{2}{*}{ Central } & 16.050 & & 40 & & 0.0025 & 9.536 & 0.0024 & & Ladakh \\
\hline & & 7 & & 15 & & & & & \\
\hline \multirow[t]{2}{*}{ South } & 13.449 & & 80 & & 0.0059 & NA & NA & & La Zhi Tang \\
\hline & & 4 & & 15 & & & & & \\
\hline \multirow[t]{2}{*}{ South } & 14.190 & & 80 & & 0.0056 & 13.820 & 0.0000 & & La Zhi Tang \\
\hline & & 11 & & 15 & & & & & \\
\hline \multirow[t]{2}{*}{ South } & 16.334 & & 80 & & 0.0049 & 15.262 & 0.0000 & & La Zhi Tang \\
\hline & & 17 & & 18 & & & & 63 & \\
\hline \multirow[t]{2}{*}{ South } & 35.049 & & 118 & & 0.0034 & 25.691 & 0.0020 & & Menshi \\
\hline & & 9 & & 10 & & & & 22 & \\
\hline \multirow[t]{2}{*}{ South } & 51.118 & & 220 & & 0.0043 & 43.084 & 0.0063 & & La Zhi Tang \\
\hline & & 26 & & 30 & & & & 33 & \\
\hline \multirow[t]{2}{*}{ South } & 97.468 & & 430 & & 0.0044 & 74.293 & 0.0045 & & Menshi \\
\hline & & 50 & & 30 & & & & 50 & \\
\hline South & 116.203 & & 430 & & 0.0037 & 106.836 & 0.0000 & & Menshi \\
\hline South & & 9 & & 10 & & & & & \\
\hline Central & 35.599 & & 220 & & 0.0067 & NA & NA & & Manikala \\
\hline South & 139.376 & 25 & 1520 & 50 & 0.0112 & 87.488 & 0.0128 & 21 & Manikala \\
\hline
\end{tabular}


Central

0.0080

173.204

0.0015

544 Table 1: Ages and offsets published in the literature (Brown et al., 2002; Chevalier et al., 545 2005a; Chevalier et al., 2012), SR and ISR presented in this study. ISR values for the 546 ages $13449 \mathrm{yr}$ and 35599 could not be computed because of lack of the reference value.

547 We adopt an arbitrary value of $5 \%$ for the $1 \sigma$ uncertainty of offsets. For the La Zhi Tang 548 terraces (south KF) where various ages are available for a same offset value, we use the 549 oldest age to compute ISR between $\sim 16 \mathrm{kyr}$ and $\sim 25 \mathrm{kyr}$. 
Click here to download high resolution image

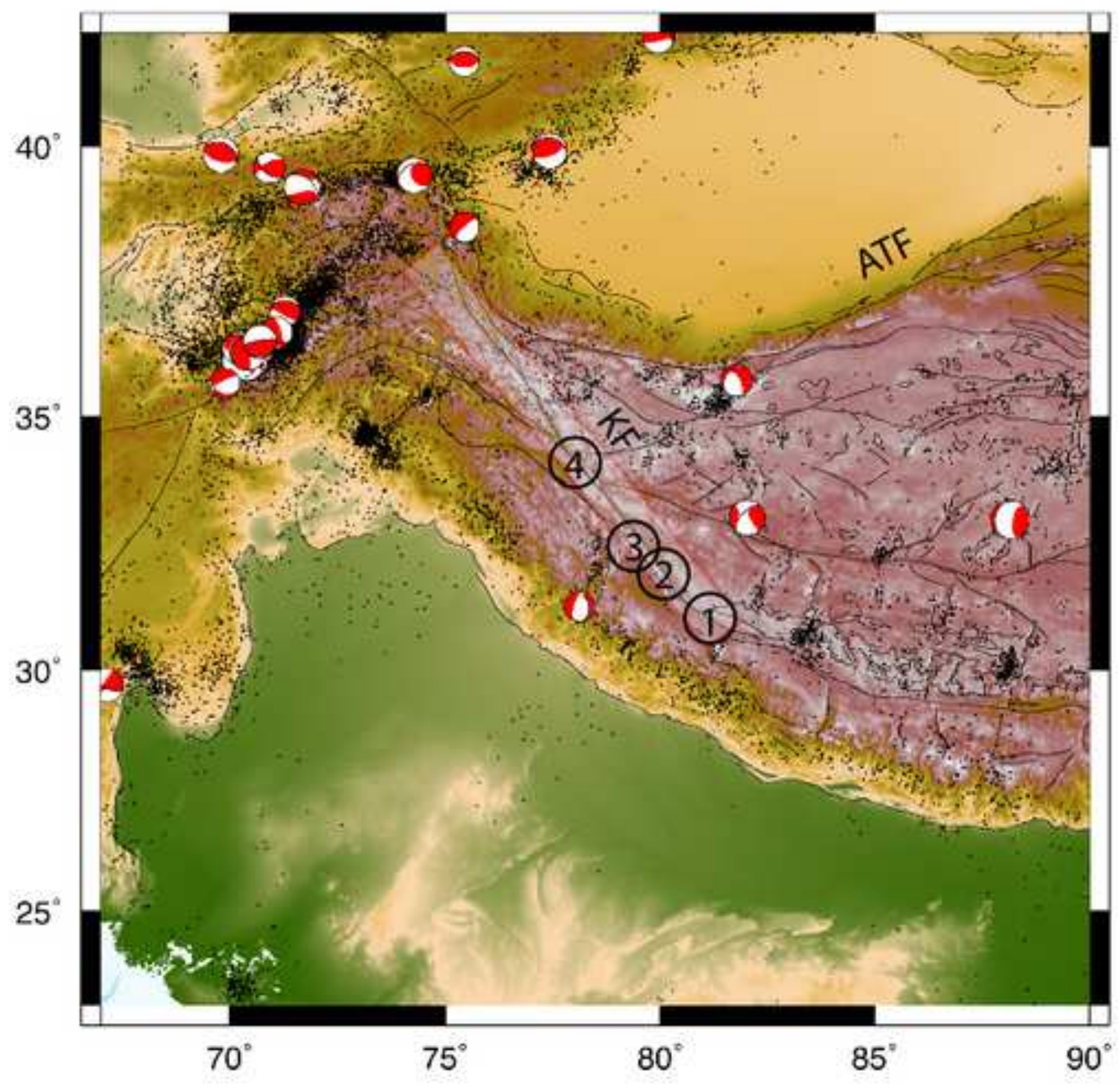




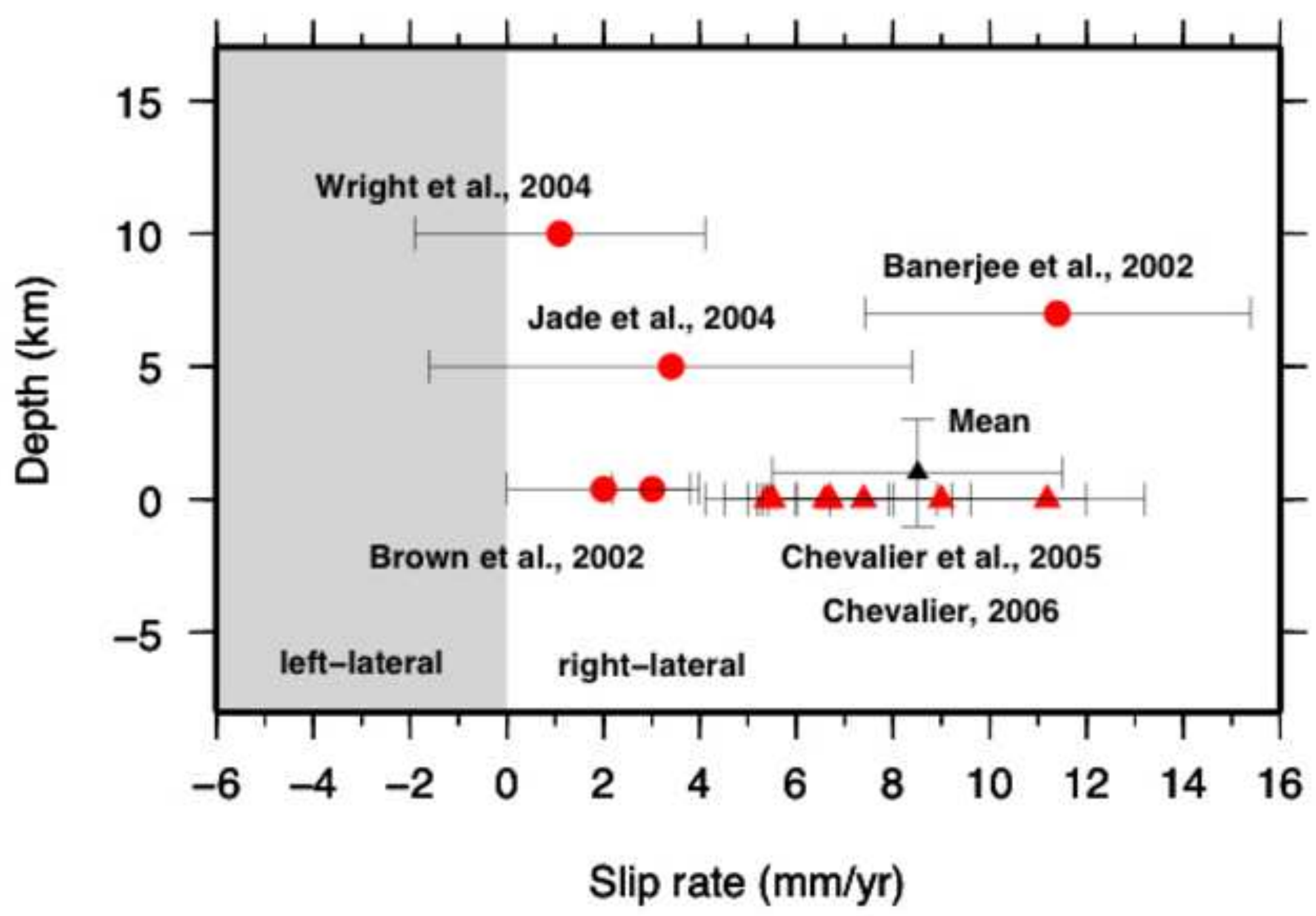




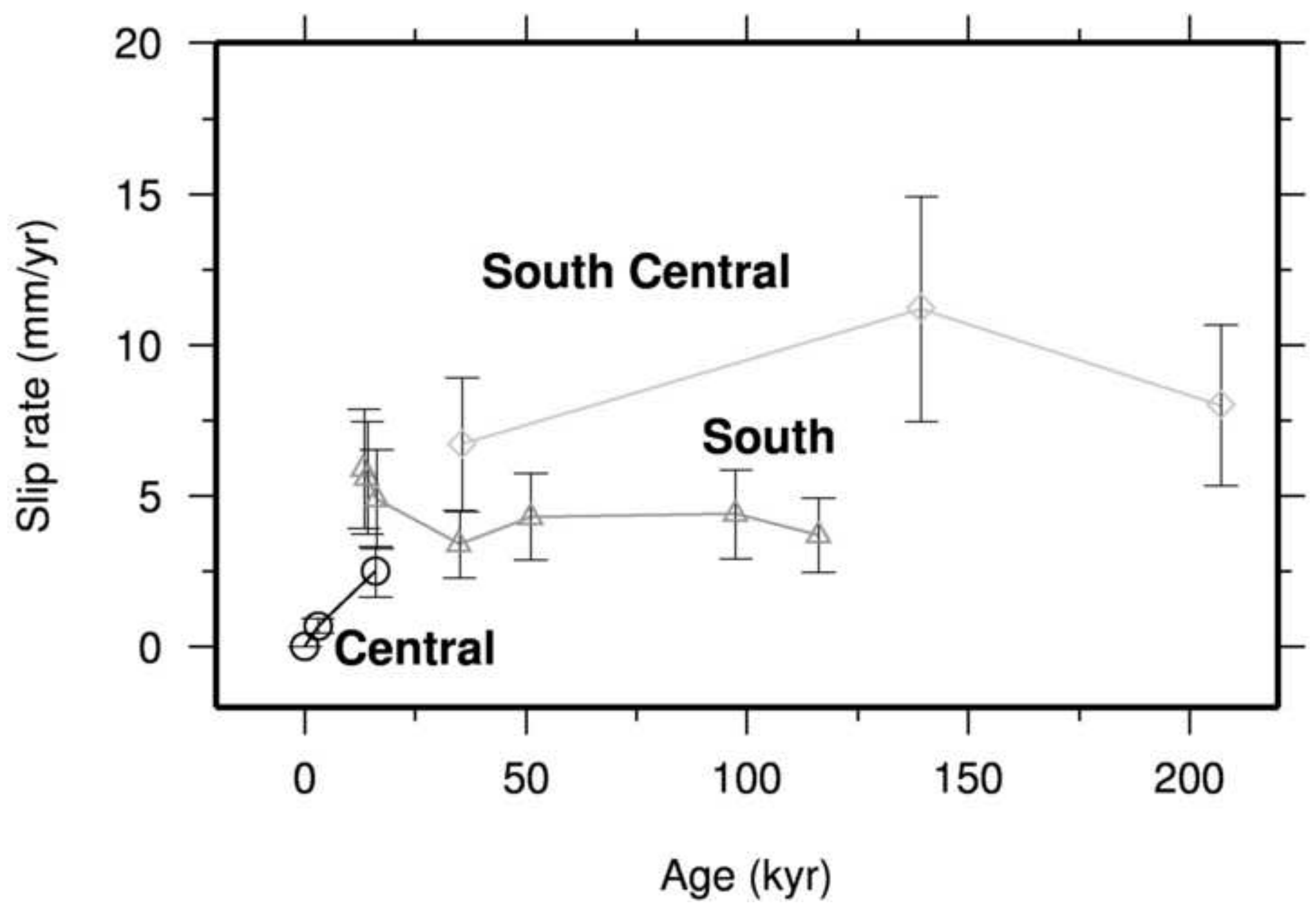




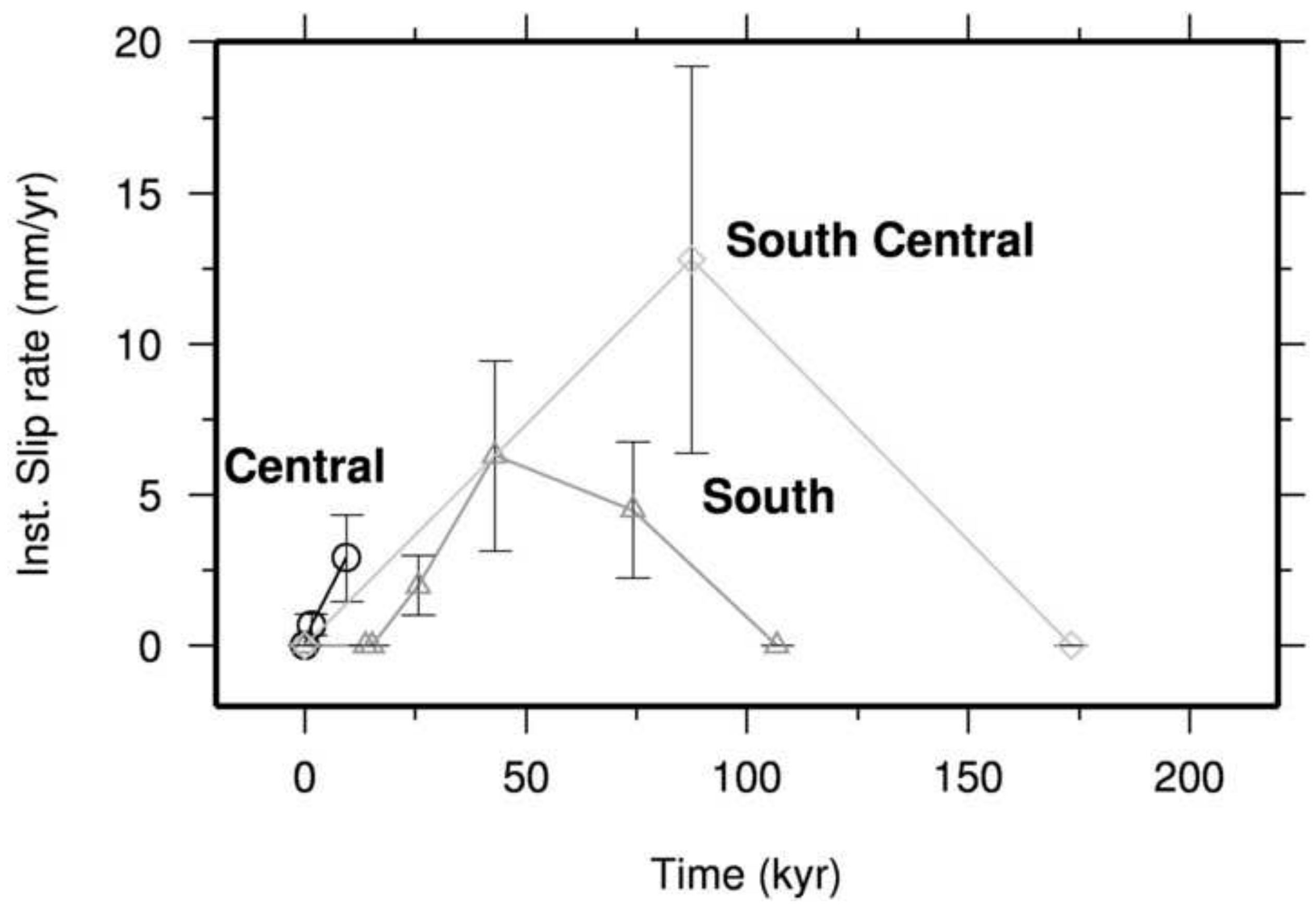


Figure3a

Click here to download high resolution image
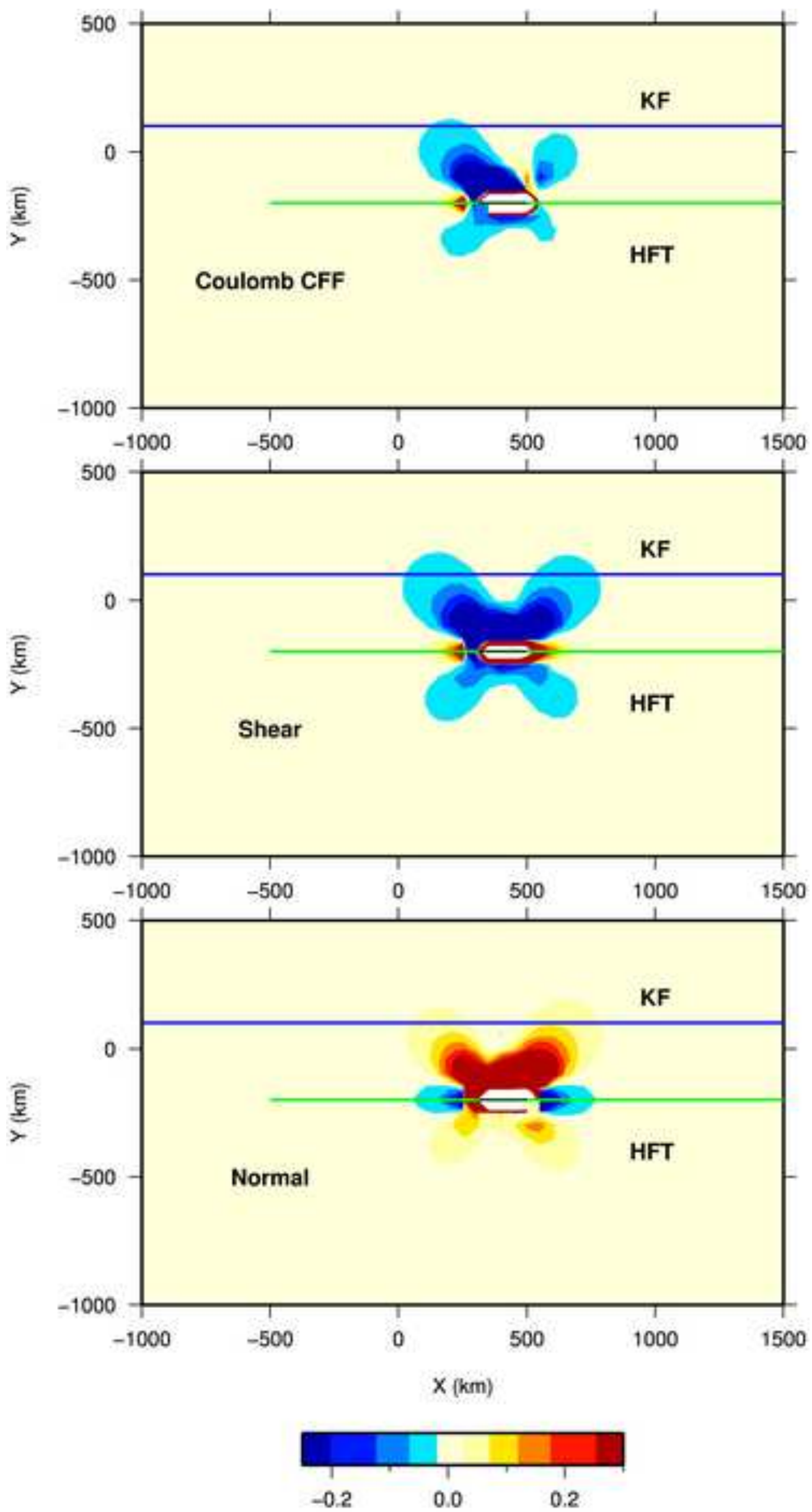

Stress change (bars) 
Figure $3 b$

Click here to download high resolution image
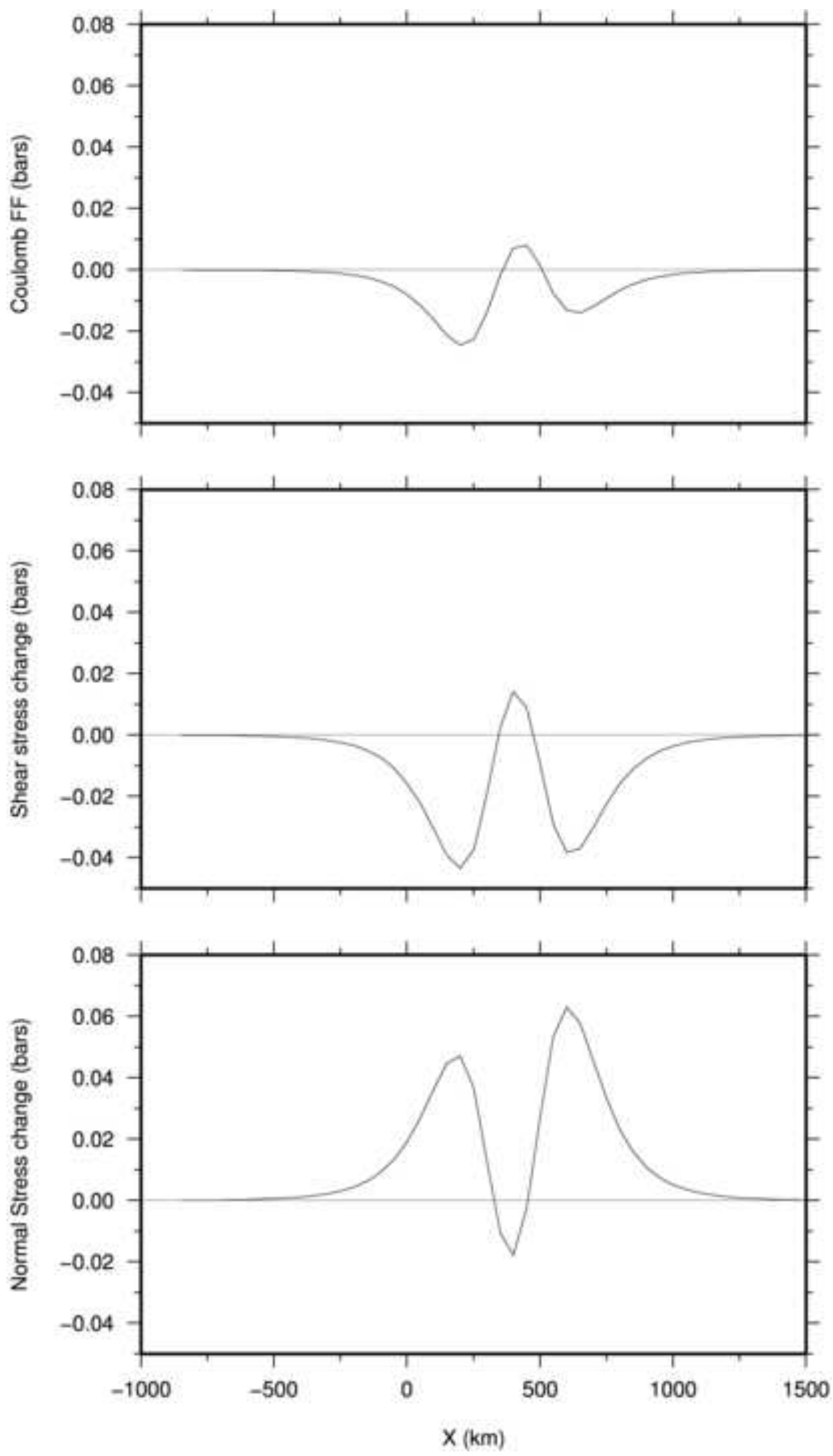
1 Quaternary Rupture Behavior of the Karakoram Fault and its relation to the dynamics of the continental lithosphere, NW Himalaya-West Tibet

$4 \quad$ Houlié, N. ${ }^{1}$ and R.J. Phillips ${ }^{2}$

$5 \quad{ }^{1}$ Institute of Geophysics, ETH, Zurich

$6 \quad{ }^{2}$ Institute of Geophysics and Tectonics, School of Earth and Environment, University of Leeds, UK

8 SUPPORTING MATERIALS

9

A. Randomized computation of the Coulomb stress change along Karakoram fault.

12 We use Coulomb3.3[Toda and Stein, 2002] to compute the shear, normal and Coulomb

13 stress changes along the KF generated by a sequence of earthquakes occurring along the 14 subducting Indian plate. We simulate the behaviour of the two faults by using two 15 discontinuities separated by $300 \mathrm{~km}$ (along the $\mathrm{Y}$ axis presented in Figure 3). We 16 randomly place earthquakes of constant magnitude (Mw8.0 for a constant slip of 11 17 meters on a fault plane of $100 \mathrm{~km} \times 12 \mathrm{~km}$ ) along the subducting plate. We neglect any 18 earthquake of smaller magnitude. This assumption is supported by the observation of 19 earthquake of limited size (Loma Prieta, Parkfield, San Simeon, Coalinga). However, as 20 observed in the nature, we do not allow for two consecutive earthquakes to happen within $21 \quad 120 \mathrm{~km}$ (Figure S2).

We computed stress changes (Figure S3) for a sequence of earthquakes. We find 23 that if the subduction zone is seismically active, the normal stress along the KF will be 24 increasing while the shear stress will tend to decrease locally making them unlikely 
candidates for future rupture planes. We then analysed whether the evolution of the stress

26 changes along the KF during the sequence. We suggest that for some locations, the shear

27 stress can be increased even for times that are late in the seismic sequence. We then

28 confirm the model presented for a single event (see main text) and for short-term

29 interaction between the two structures.

30 The second observation is that because the subduction zone stops at $\mathrm{X}=-500 \mathrm{~km}$,

31 the stress field along the KF for $\mathrm{X}<-600 \mathrm{~km}$ is not affected by the subduction activity.

32 This implies that the triggering of an event is unlikely but also that the stress accumulated

33 in that section of KF can remain high for a long time.

34

35

36

37

38

39

40 
B. Figures and Tables.

42
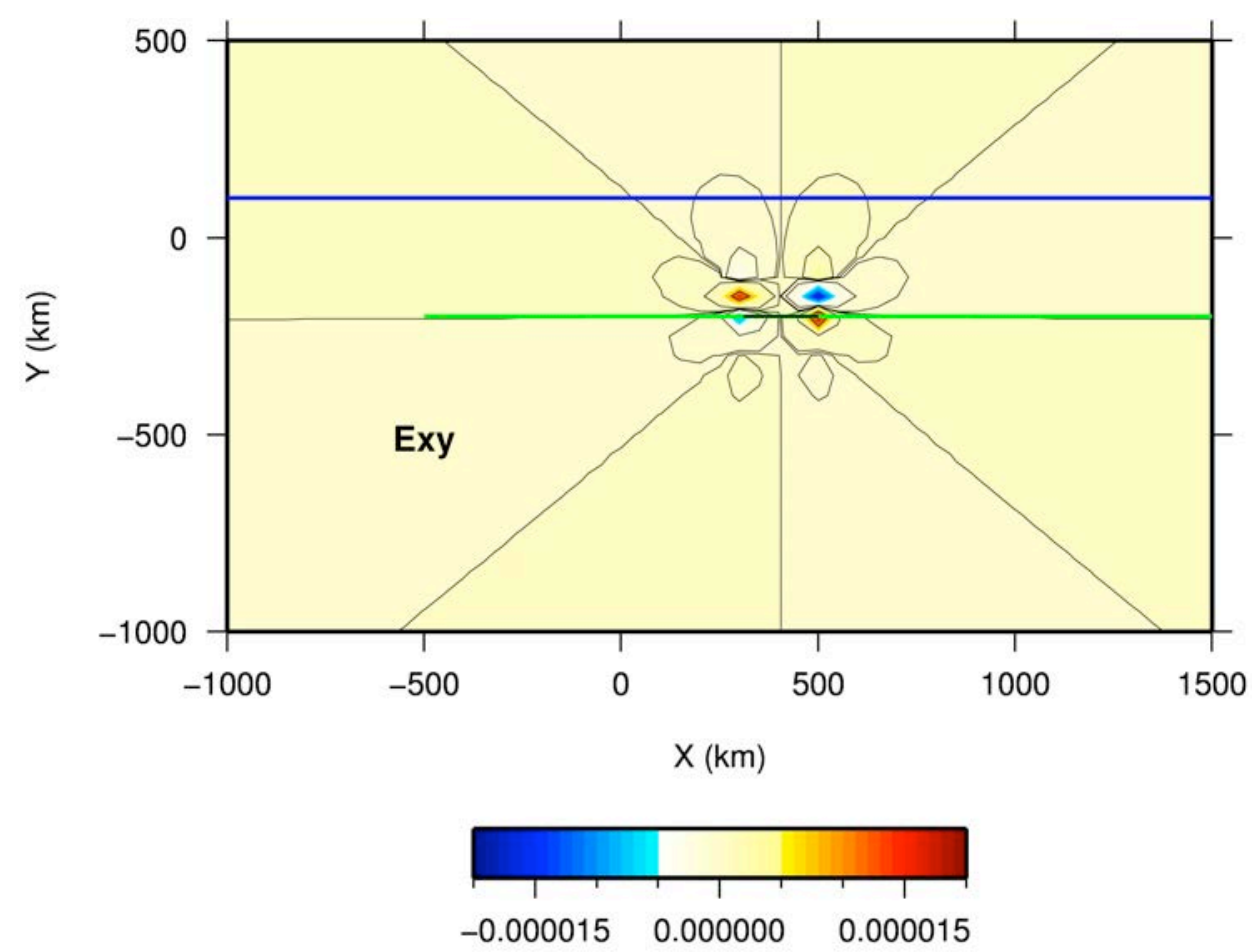

44 Figure S1. Exy strain induced by a M8.0 along the subducting plate. We contoured a 45 selection of values $\left( \pm 10^{-7}, \pm 10^{-6}, 0, \pm 10^{-5}\right.$ and $\pm 2.10^{-5}$ strain $)$. 


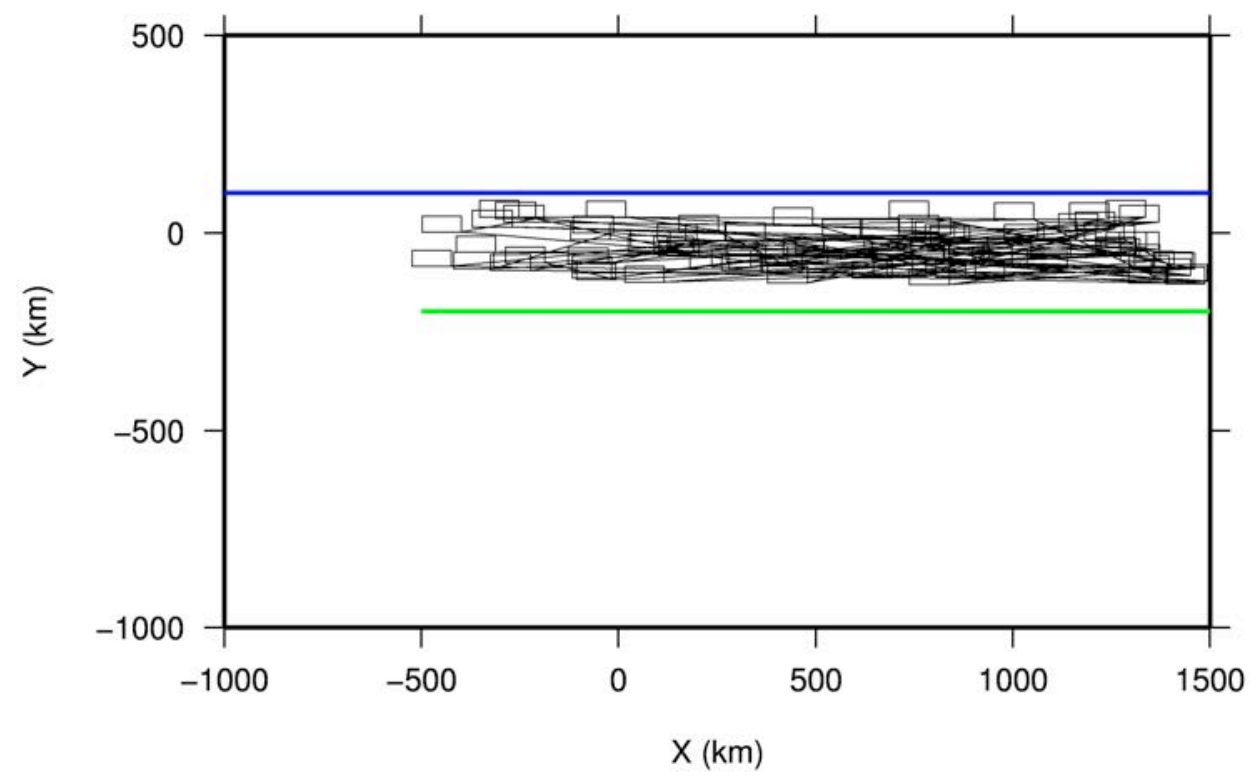

50 Figure S2. Position of the ruptured areas for the seismic sequence. KF is symbolized by a

51 blue line at $\mathrm{Y}=100 \mathrm{~km}$. The Himalyan trust front is indicated by the green line at $\mathrm{Y}=$ -

$52 \quad 200 \mathrm{~km}$. The black lines indicated the projection of the fault planes with the surface. 

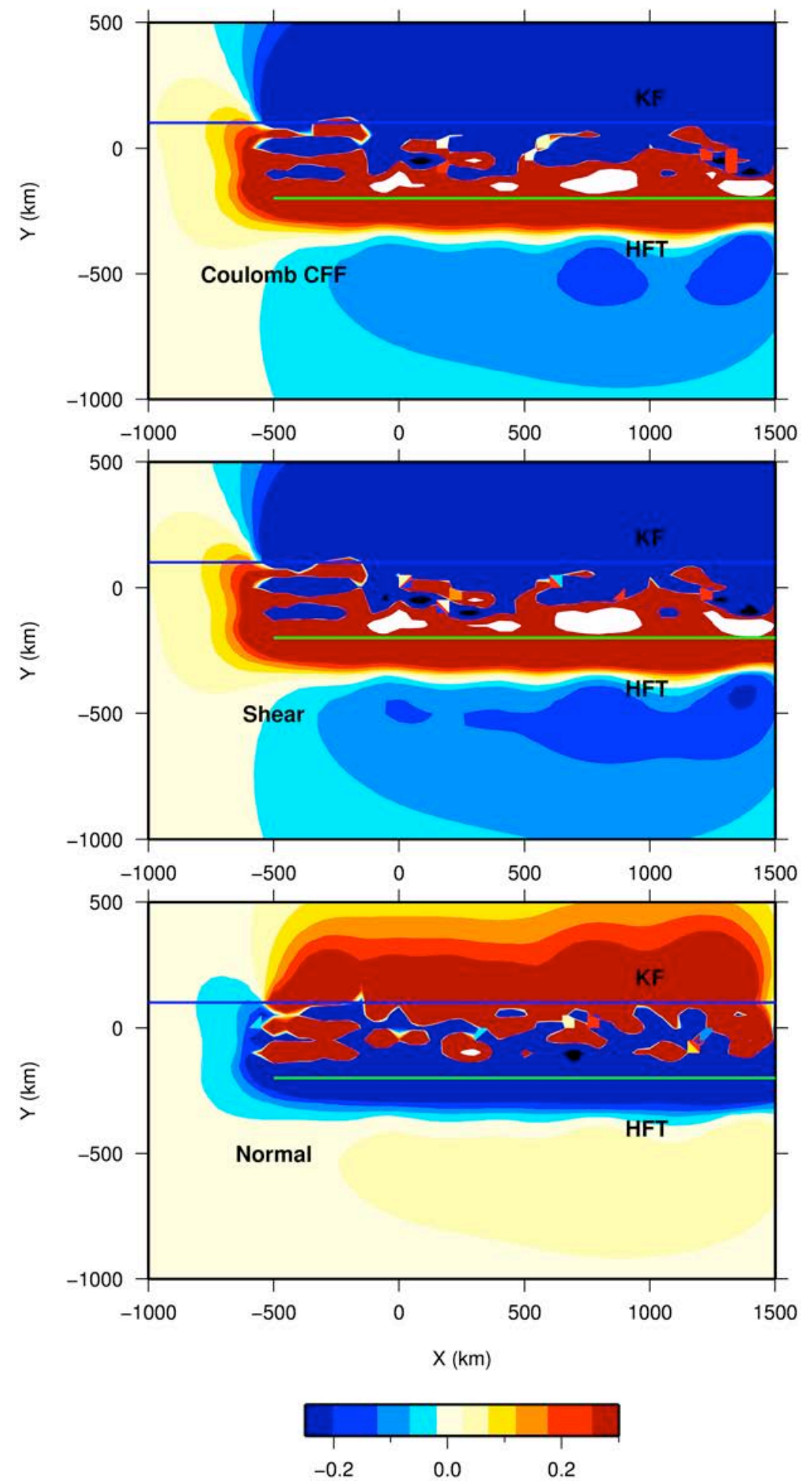

56 Figure S3: Coulomb, shear and normal stress changes associated with a seismic

57 sequence. We find that even with distant seismicity the KF stress state is affected by a 

seismic sequence along HTF. This suggests that whenever the subduction zone is active,

59 the Karakoram Fault would not be able to slide/slip.

60

61

62

63
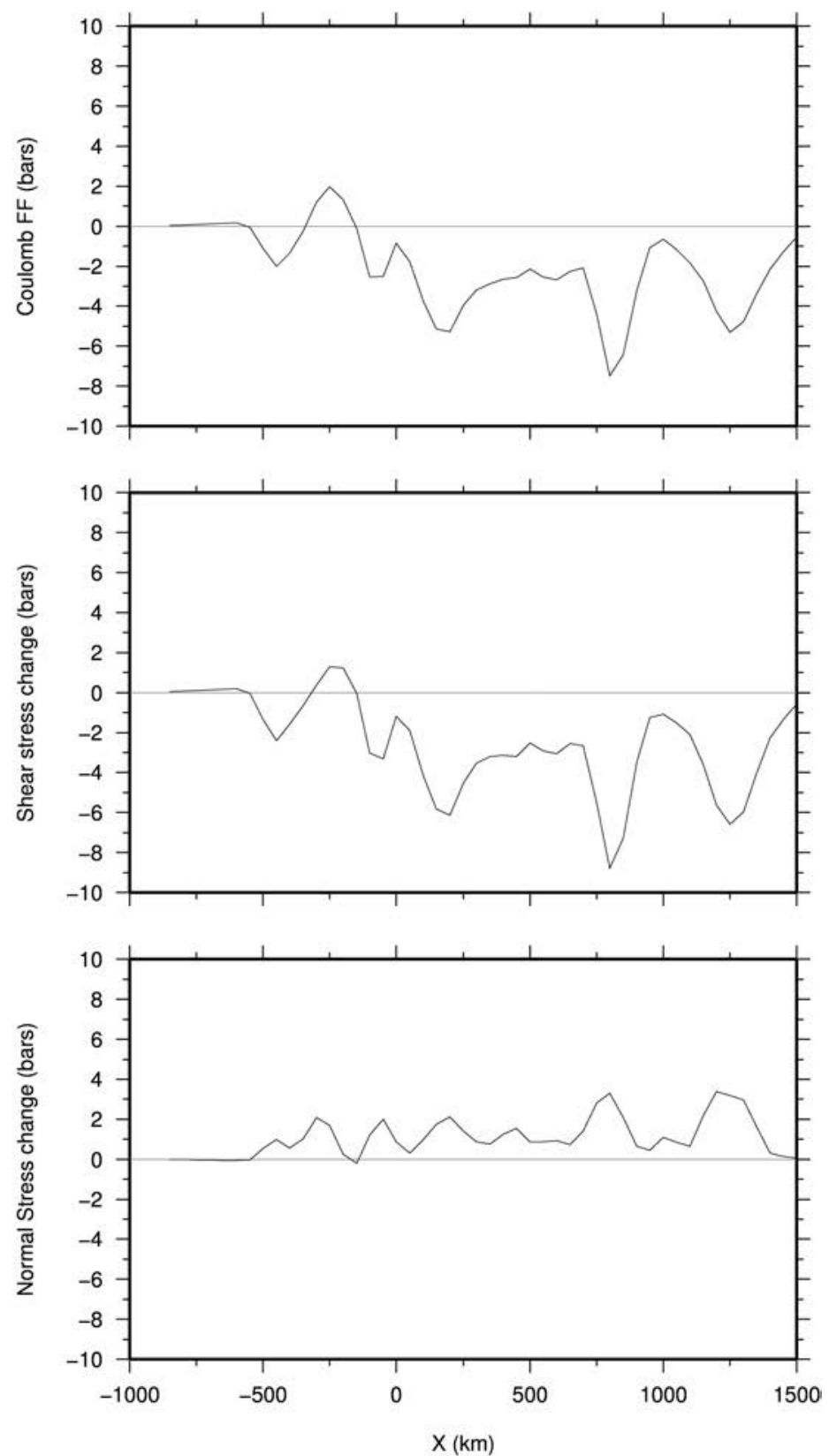

64

66 Figure S4: Same as Figure 3b for the long-term term randomized seismic sequence. 

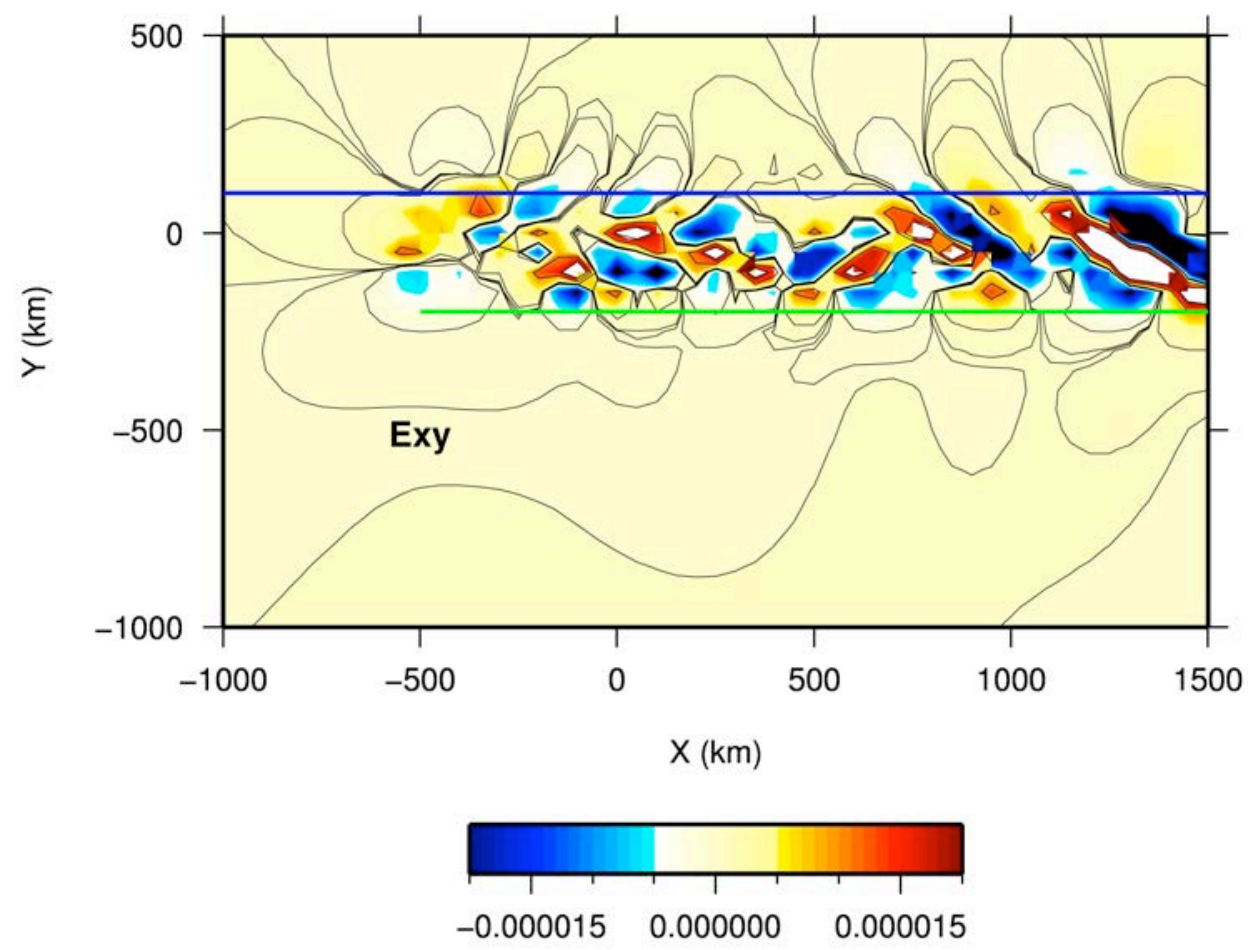

67

Strain change

68

69 Figure S5: Accumulated strain generated by long-term seismic activity along HTF. 70 


\begin{tabular}{|c|cc|c|c|}
\hline Mw & L, km & W, km & Max. depth, km & Slip, m \\
\hline 7 & 48.97 & 15.48 & 10.07 & 1.55 \\
7.25 & 68.78 & 18.62 & 12.10 & 2.18 \\
7.5 & 96.60 & 22.38 & 14.55 & 3.07 \\
7.75 & 135.67 & 26.91 & 17.50 & 4.31 \\
8 & 190.54 & 32.35 & 21.04 & 6.06 \\
8.25 & 267.60 & 38.90 & 25.29 & 8.51 \\
8.5 & 375.83 & 46.77 & 30.41 & \\
\hline
\end{tabular}

73

74 Table S1: Parameters for simulated earthquakes along the collisional zone in the NW

75 Himalaya. Slip, and source geometry parameters were computed. The magnitude of an

76 earthquake is function of both Length (L) and Width (W) of the ruptured fault

77 segment[Wells and Coppersmith, 1994]. We computed slip and source geometry

78 parameters for events that could affect the KF area. 